\title{
“MUTAÇÃO À BRASILEIRA”: UMA ANÁLISE EMPÍRICA DO ART. 52, X, DA CONSTITUIÇÃO*
}

\author{
Carlos Victor Nascimento dos Santos
}

"BRAZILIAN MODE MUTATION": AN EMPIRICAL ANALYSIS

OF THE ARTICLE 52, X OF THE 1988 CONSTITUTION

\section{RESUMO}

O OBJETIVO DO PRESENTE ESTUDO É TESTAR A PLAUSIBILIDADE DA TESE DE QUE TERIA OCORRIDO MUTAÇ̃̃O CONSTITUCIONAL NO SISTEMA DE CONTROLE DE CONSTITUCIONALIDADE NO BRASIL, ESPECIFICAMENTE QUANTO À COMPETENNCIA CONFERIDA PELA Constituicão ao Senado Federal PARA SUSPEnder a eficácia DE LEI OU ATO NORMATIVO DECLARADO INCONSTITUCIONAL NO CONTROLE DIFUSO DE CONSTITUCIONALIDADE. ESSE ARGUMENTO fol empregado pelo Ministro Gilmar Mendes, do Supremo Tribunal Federal, nO JULGamento dA RECLAMACÃ̃ 4.335-5/AC. PARA ANALISAR A CONSISTENNCIA DESSA TESE, REALIZOU-SE UMA ANÁLISE EMPÍRICA DO PAPEL DO SENADO FEDERAL DIANTE DO ART. 52, X, DA CONSTITUiçÃo. COMO RESUltado, DEFENDE-SE NÃO SER POSSÍVEL DAR PLAUSIBILIDADE A ESSE TIPO DE ARGUMENTAÇÃO APENAS TENDO POR BASE JURISPRUDÊNCIA, DOUTRINA E ARGUMENTACÃO TIPICAMENTE CONSTITUCIONAL, NECESSITANDO DE BASE EMPÍRICA QUE O PERMITA ATRIBUIR MAIS SOLIDEZ E CONSISTÊNCIA A QUALQUER ARGUMENTO DE MUTAÇĀO CONSTITUCIONAL NA ORDEM JURÍDICA BRASILEIRA.

\section{PALAVRAS-CHAVE}

Controle difuso de constitucionalidade; Mutação constitucional; Supremo Tribunal Federal; Senado Federal; Separação de Poderes.

\begin{abstract}
THE GOAL OF THIS STUDY IS TO ASSESS THE SOUNDNESS OF THE THESIS THAT THE BRAZILIAN SYSTEM OF DIFFUSE JUDICIAL REVIEW HAS UNDERGONE A "CONSTITUTIONAL MUTATION", SPECIFICALLY REGARDING THE FEDERAL SENATE'S CONSTITUTIONAL PREROGATIVE TO SUSPEND THE ENFORCEMENT OF ANY LAW OR NORMATIVE ACT THAT HAS BEEN DECLARED UNCONSTITUTIONAL BY THE SUPREME FEDERAL COURT BY MEANS OF CONCRETE REVIEW. THIS "CONSTITUTIONAL MUTATION" ARGUMENT HAS BEEN EMPLOYED BY JUSTICE GILMAR FERREIRA MENDES IN THE JUDGMENT OF THE RECLAMAÇÃO 4.335-5/AC BY THE BRAZILIAN SUPREME FEDERAL COURT. TO ASSESS THE CONSISTENCY OF THIS THESIS, THIS PAPER DOES AN EMPIRICAL ANALYSIS OF THE ROLE OF THE BRAZILIAN SENATE IN USING THE POWERS CONFERRED TO IT BY ARTICLE 52 , $X$, OF THE 1988 CONSTITUTION. THIS ARGUMENT ALSO SUPPORTS THE IDEA THAT ANY INSTANCES OF CONSTITUTIONAL REASONING BASED ON "CONSTITUTIONAL MUTATION" CANNOT BE GROUNDED ONLY ON DOCTRINAL AND JURISPRUDENTIAL INPUTS AND REQUIRE EMPIRICAL ANALYSIS IN ORDER TO BE JUSTIFIED.
\end{abstract}

\section{KEYWORDS}

DIFFUSE JUDICIAL REVIEW; CONSTITUTIONAL MUTATION; Supreme Federal Court; Federal Senate; Separation OF POWERS.

\section{INTRODUÇÃO}

$\mathrm{O}$ ordenamento jurídico brasileiro vem sofrendo grandes modificações em sua ordem constitucional, principalmente após a promulgação da Constituição Federal de 1988. Após o processo de redemocratização no Brasil, fazia-se extremamente necessário criar mecanismos mais efetivos de proteção aos direitos fundamentais. E, pela 
evolução histórico-política da ordem constitucional brasileira, não se poderia desenvolver uma Constituição que não fosse caracterizada como rígida, isto é, uma Constituição que estabelecesse procedimentos mais rígidos à sua modificação, principalmente quanto ao quorum de aprovação de suas emendas, no que se refere à adição, supressão ou alteração de suas normas.

No processo de elaboração da Constituição, os constituintes responderam a diversas aspirações da sociedade civil. Foram refletidos na Constituição não só os instrumentos de defesa e efetivação dos direitos fundamentais, mas a delimitação do alcance do que se exige do poder estatal, sendo estabelecidos limites materiais à modificação do texto constitucional. ${ }^{1}$ Os referidos limites materiais impostos pelos constituintes não necessariamente levam a um engessamento da Constituição, embora tenham como um dos objetivos evitar modificações temerárias, como a diminuição da garantia aos direitos fundamentais, por exemplo. As novas demandas da sociedade civil sempre terão de ser levadas em consideração, até mesmo para se evitar um hiato entre a Constituição vigente e a realidade da sociedade civil brasileira.

Assim, é possível notar que a Constituição é transformada para acompanhar os processos de mudanças de comportamentos da sociedade, o que não significa que tais mudanças sejam necessariamente feitas com substancial alteração do texto constitucional. Podem-se depreender duas outras possíveis formas de alteração da Constituição: mudanças por interpretação judicial e mutação do texto constitucional. O presente texto abordará a segunda dessas outras formas possíveis, que fora invocada pelo Ministro Gilmar Mendes no voto proferido dos autos da Reclamação 4.335-5/ AC.

A mutação constitucional insere-se em um espaço que pressupõe uma progressividade da realidade social, trazendo uma análise praticamente entre o passado - significado e sentido que a norma ganhou no momento de sua criação - e o presente - sentido que a mesma norma traduz diante de nova realidade social. Para compreendê-la, torna-se fundamental um olhar cuidadoso à norma, ao contexto social e político que estava inserida quando foi criada, e a realidade social circundante. Assim, o fenômeno da mutação constitucional deve ser mais bem compreendido como modificações de sentidos dos textos constitucionais, sem qualquer alteração em sua estrutura, i.e., sem revisões ou emendas. Por tal entendimento, pode-se depreender que a mutação denota algumas mudanças de sentidos de texto lógicas e inevitáveis, por conta das constantes transformações da realidade social.

A mutação constitucional, então, consistiria em mudanças de sentido, e não na estrutura das palavras existentes no texto constitucional a partir de um processo de transformações de comportamentos não organizados, difusos, em que não se torna possível a identificação de uma ingerência formal do Poder Constituinte Derivado. Diferentemente da aplicação dos preceitos constitucionais aos casos concretos, na mutação constitucional tem-se um reconhecimento de repetidos comportamentos unidos por uma aceitação implícita, capaz de lhe atribuir caráter geral e abstrato como se 
norma fosse (FERRAZ, 1986). Assim, a mudança de sentido de preceitos constitucionais tem por objetivo uma possível adaptação destes aos fatos que se insurgem, de forma espontânea, sem seguir procedimentos formais como no processo de emendas à Constituição. ${ }^{2}$

Apesar dessa abordagem, não é objetivo do presente texto discutir a "mutação constitucional" enquanto conceito, mas o seu reconhecimento na tese sustentada pelo Ministro Gilmar Mendes. Para ele, o art. 52, X, da Constituição Federal tem, atualmente, sentido de apenas atribuir publicidade às decisões proferidas pelo Supremo Tribunal Federal, em se tratando de controle difuso. Por consequência, haveria uma aproximação das diferentes espécies de controle de constitucionalidade existentes no sistema brasileiro: difuso e abstrato, permitindo, então, que, de acordo com a tese defendida por Gilmar Mendes, as decisões proferidas pelo Plenário do Supremo Tribunal Federal, mesmo em se tratando de controle difuso de constitucionalidade, sejam dotadas de efeitos erga omnes e vinculantes. Isso porque, no caso a ser analisado, o Ministro lança argumentos no sentido de já existirem mudanças relacionadas principalmente com a competência do Senado Federal frente ao controle difuso de constitucionalidade. Assim, sua posição se apresenta tão somente como o reconhecimento de tais mudanças, que delimitam o âmbito de atuação do Senado no controle difuso.

Para fins de verificação da plausibilidade do referido argumento, que tem um caráter inclusive empírico, será feita uma apreciação da solidez dos argumentos sustentados pelo Ministro Gilmar Mendes na defesa de sua tese jurídica da "mutação constitucional” do art. 52, X, da Constituição. A metodologia utilizada para a construção de tais dados será apresentada no tópico seguinte.

\section{ANÁlise EMPÍrica dos PRESSUPOSTOS DA ARGUMENTAÇÃo do Ministro Gilmar Mendes no voto proferido nos autos DA RCL 4.335-5/AC}

Os argumentos lançados pelo Ministro Gilmar Mendes em voto proferido nos autos da Rcl 4.335-5 / AC expressam uma aproximação desses dois sistemas de controle de constitucionalidade que coexistem no Brasil - aproximação essa defendida com base na tese de que ocorreu uma mutação constitucional do art. 52, X, da Constituição Federal. Por tal raciocínio, o Ministro Gilmar Mendes deduz que o Senado Federal não mais teria a faculdade de suspender a eficácia de lei ou ato normativo declarado inconstitucional pelo Plenário do Supremo Tribunal Federal, mas seria dotado apenas da função de atribuir publicidade à decisão proferida por essa Corte. Isto é, se adotada a tese do Ministro Mendes, os efeitos gerados em sede de controle difuso de constitucionalidade alcançariam a todas as pessoas e órgãos do Poder Judiciário e da Administração Pública direta e indireta. 


\section{i. I Apontamentos metodológicos}

$\mathrm{Na}$ busca pela pesquisa para o desenvolvimento do presente estudo, percebeu-se a necessidade de coleta de alguns dados essenciais à compreensão da matéria em análise. Para ser possível identificar se o Senado Federal utilizava efetivamente a competência concedida pela Constituição Federal, em seu art. 52, X, foi preciso quantificar o número de acórdãos proferidos pelo Plenário do Supremo Tribunal Federal ${ }^{3}$ e o de resoluções expedidas pelo Senado, suspendendo a execução de leis ou atos normativos declarados inconstitucionais pelo Plenário do STF, no período de 1989 a 2009 (ano da última base de dados possível de análise). Há que se destacar que, para fins de facilitação da pesquisa, foram analisados os acórdãos que declararam inconstitucionalidade de leis ou atos normativos, ocorridas no controle difuso, somente por meio de recurso extraordinário, sabendo-se que é possível também que ocorram em sede de outros instrumentos processuais, como mandado de segurança, habeas corpus etc.

A coleta de dados se deu nos sítios do Supremo Tribunal Federal - bem como por meio de sua Secretaria de Informática, Coordenadoria de Acórdãos e Secretaria de Apoio aos Julgamentos - e do Senado Federal. Além desses, também se coletaram dados da revista Análise Justiça (2006), demonstrando uma radiografia do Supremo Tribunal Federal e do Superior Tribunal de Justiça.

No primeiro momento, buscou-se o número de resoluções expedidas pelo Senado Federal, de 1988 a 2009. Dentre todas elas, por meio da simples leitura de cada uma, foram separadas somente aquelas que suspendiam eficácia de lei ou ato normativo declarado inconstitucional pelo Plenário do STF em sede de recurso extraordinário, desde que o acórdão tivesse sido enviado ao Senado pelo STF. Por meio dessa análise, foi possível obter o número de resoluções em que o Senado Federal fazia uso da competência atribuída pelo art. 52, X, da Constituição Federal, no dado período.

Posteriormente, utilizou-se uma base de dados, feita pelo pesquisador Pablo Cerdeira, da Escola de Direito da Fundação Getulio Vargas do Rio de Janeiro, a partir de um spider ${ }^{4}$ desenvolvido para buscar e compilar dados do Supremo Tribunal Federal. Além disso, foram consultadas a Secretaria de Informática, Coordenadoria de Acórdãos e Secretaria de Apoio aos Julgamentos, todas do STF, a fim de perceber traços comuns entre as informações por elas fornecidas e os elementos extraídos da base de dados. Nela, estão inclusas tanto as decisões monocráticas quanto os acórdãos proferidos por Turmas e Plenário do STF, no período de 1990 a 2009. De todos os recursos extraordinários existentes na base de dados, separaram-se os que foram providos, quer seja total ou parcialmente, dos não providos. E, mesmo em relação aos que foram julgados parcialmente, foram separados os que tiveram declaração de inconstitucionalidade de lei ou ato normativo e, posteriormente, foram enviados ao Senado para o exercício da competência conferida pelo art. 52, X, da CF. Dos recursos extraordinários que foram providos, total ou parcialmente, foi feita uma coleta 
acerca do número de recursos extraordinários julgados pelo Plenário do Supremo Tribunal Federal, onde houve comunicação da decisão do STF ao Senado Federal.

A partir desse dado, buscou-se analisar a relação entre a quantidade de acórdãos do STF, proferidos em sede de recurso extraordinário, em que havia comunicação com o Senado Federal, para o exercício da competência conferida pelo art. 52, X, da Constituição Federal, e o número de resoluções expedidas pelo Senado em que fazia uso efetivo de tal competência.

Se, por um lado, os dados mostraram que o Supremo Tribunal Federal cumpre com um de seus papéis institucionais, inclusive previsto em seu Regimento Interno, ${ }^{5}$ como o de comunicar as decisões tomadas no controle difuso de constitucionalidade ao Senado Federal, e este não fizer uso da competência que lhe confere o art. 52, X, da Constituição Federal, será plausível argumentar que estamos diante de uma mutação constitucional.

Por outro lado, se a análise dos dados revelar que o Senado faz um uso mínimo de sua competência, suspendendo total ou parcialmente ao menos algumas das decisões proferidas pelo Plenário do STF e comunicadas ao Senado Federal, os argumentos suscitados pelo Ministro Gilmar Mendes serão enfraquecidos. De fato, se verificarmos que o Senado tem cumprido com a competência que a Constituição Federal lhe confere, não estariam preenchidos os elementos necessários à identificação de uma autêntica mutação constitucional, restando enfraquecida uma premissa importante do argumento desenvolvido pelo Ministro Gilmar Mendes.

Por fim, pode ser que, na análise dos dados, faltem elementos necessários para qualquer conclusão sólida. Mas, mesmo nesta hipótese, os dados já terão chamado a atenção para uma importante questão: não há falar em autêntica mutação constitucional de forma intuitiva, ou por meio de argumentação constitucional puramente doutrinária ou conceitual. É preciso fazer a análise dos elementos que a caracterizam, que a justificam para, somente após esse processo, ser possível discutir se se verifica ou não a manifestação de tal fenômeno.

\section{I.2 Dados referentes Às resoluções expedidas Pelo Senado Federal}

Para que possamos investigar se o Senado tem usado a competência prevista no art. 52, $\mathrm{X}$, da Constituição, devemos averiguar: a) quantos recursos extraordinários foram decididos com declaração de inconstitucionalidade pelo Plenário do STF (Coluna 1); b) quantas dessas decisões em sede de recurso extraordinário resultaram em comunicações ao Senado, instando-o a utilizar sua competência prevista no art.52, X (Coluna 2); c) por fim, quantas dessas comunicações resultaram em suspensões, por parte do Senado, da execução das leis objeto das comunicações feitas pelo STF.

Partindo da linha investigativa desenhada, o trabalho ora desenvolvido iniciou sua pesquisa com base nos dados disponibilizados pelo sítio do Supremo Tribunal Federal. Assim, da referida base de dados, onde se pôde verificar a existência de 470.239 
recursos extraordinários, distribuídos entre 1988 a 2010, o presente trabalho se utilizou da análise de 372.961 deles, compreendidos no período de 1989 a 2009, por ser o quantitativo disponível na base de dados do spider desenvolvido pelo pesquisador da Fundação Getulio Vargas. Entre os recursos analisados, isto é, dos 372.961, estão todos aqueles decididos monocraticamente, por Turmas ou pelo Plenário do STF.

Dos 372.961 recursos extraordinários constantes na base de dados, 97.130 foram providos, total ou parcialmente, de forma monocrática, por Turma ou Plenário, e 5.192 foram não providos. Desses 97.130 recursos extraordinários, identificaram-se apenas 165 em que houve comunicação com o Senado. Contudo, em nem todas essas comunicações estava em jogo a suspensão de leis declaradas inconstitucionais pelo STF, isto é, nem todas as 165 ocorrências de comunicação ao Senado de decisões do STF em sede de RE representavam oportunidades para o Senado utilizar a competência prevista no art. 52, X, da Constituição. Por isso, procedeu-se a uma análise individual de conteúdo dos 165 recursos, com base na qual foram extraídos 136 que foram providos total ou parcialmente, declarando inconstitucionalidade de lei ou ato normativo e que foram comunicados ao Senado para uso efetivo de sua competência. Esses 136 recursos extraordinários estão compreendidos no período de 1990 a 2008, sendo analisados, individualmente, por meio de todos os dados acessíveis a eles no sítio do Supremo Tribunal Federal. ${ }^{6}$

O número de apenas 136 recursos extraordinários, providos pelo Plenário, em que houve efetiva comunicação do STF com o Senado Federal para fins do constante no art. 52, X, é um dado fundamental para a análise dos argumentos lançados pelo Ministro Gilmar Mendes. Isso porque, se considerarmos que o Senado Federal faz pouco uso da expedição de resoluções para suspender a eficácia de leis ou atos normativos declarados inconstitucionais pelo STF, é possível que tal competência não seja importante no desenho institucional brasileiro, o que fortaleceria o argumento quanto à índole meramente histórica da atribuição de tal competência ao Senado, conforme o defendido pelo Ministro Gilmar, no voto proferido nos autos da Rcl 4.335-5/ AC.

O número de apenas 136 recursos providos, total ou parcialmente, em que houve comunicação da decisão ao Senado revela a possibilidade de o Supremo Tribunal Federal, por meio da sua postura, principalmente em relação ao mandamento de seu Regimento Interno, não estar efetivamente comunicando suas decisões ao Senado. Esses 136 representam apenas $0,1 \%$ dos 97.130 recursos extraordinários que foram providos, total ou parcialmente, pelo Plenário do STF, e que deveriam ter a sua decisão comunicada ao Senado. Tal questão poderá ser mais bem compreendida adiante.

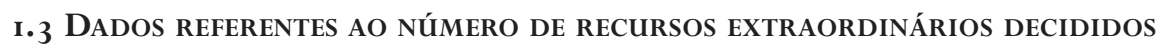 pelo Plenário do STF, com comunicação feita ao Senado Federal}

Mesmo com os dados descritos, faltava ainda a análise de outro importante dado: o número de resoluções expedidas pelo Senado, fazendo o uso do art. 52, X, da 
Constituição Federal. Sem o referido dado, não seria possível confrontar o número de resoluções expedidas pelo Senado com o número de recursos extraordinários em que o Plenário do STF fez o controle difuso de normas, declarando a inconstitucionalidade de leis ou ato normativos, e que comunicou tais decisões ao Senado Federal. Para obtenção desse importante dado, responsável também pela construção e atribuição de sentido à pesquisa ora realizada, utilizaram-se como base de dados as resoluções expedidas pelo Senado, de 1988 a 2008, isto é, todas as constantes em seu sítio. Assim, todas as resoluções foram individualmente analisadas, para separar aquelas em que se fazia uso efetivo da competência concedida pela Constituição Federal, constante no art. 52, X, obtendo-se, assim, os seguintes dados:

\section{tabela 1 - Resoluções expedidas pelo Senado Federal}

\begin{tabular}{|c|c|c|c|}
\hline ANO & $\begin{array}{l}\text { TOTAL DE RESOLUÇÕES } \\
\text { EXPEDIDAS PELO SENADO }\end{array}$ & $\begin{array}{l}\text { RESOLUČ̃̃ES EXPEDIDAS } \\
\text { EM RAZẪO DO ART. } 52 \text {, } \\
\text { X, DA CF }\end{array}$ & $\begin{array}{l}\text { RESOLUČ̃̃ES EXPEDIDAS } \\
\text { EM RAZÃO DO ART. } 52, X, \text { DA } \\
\text { CF, POR DECISÃO DEFINITIVA } \\
\text { DO STF EM RE }\end{array}$ \\
\hline 1989 & 106 & 3 & 2 \\
\hline 1990 & 88 & 4 & 4 \\
\hline 1991 & 91 & 4 & 4 \\
\hline 1992 & 101 & 0 & 0 \\
\hline 1993 & 150 & 3 & 3 \\
\hline 1994 & 97 & 0 & 0 \\
\hline 1995 & 76 & 12 & 11 \\
\hline 1996 & 111 & 6 & 4 \\
\hline 1997 & 136 & 3 & 1 \\
\hline 1998 & 112 & 0 & 0 \\
\hline 1999 & 81 & 11 & 11 \\
\hline 2000 & 77 & 0 & 0 \\
\hline 2001 & 43 & 0 & 0 \\
\hline 2002 & 66 & 0 & 0 \\
\hline 2003 & 22 & 0 & 0 \\
\hline 2004 & 22 & 0 & 0 \\
\hline
\end{tabular}




\begin{tabular}{llll}
2005 & 68 & 43 & 35 \\
\hline 2006 & 71 & 8 & 6 \\
\hline 2007 & 49 & 15 & 13 \\
\hline 2008 & 49 & 4 & 1 \\
\hline TOTAL & 1616 & 110 & 95 \\
\hline
\end{tabular}

Fonte: site do Senado Federal.

Levando-se em consideração as informações extraídas pelos gráficos, pode-se perceber que há momentos em que ocorre um significativo aumento na expedição de resoluções, como no período 2005-2007, em que foram expedidas 54 resoluções pelo Senado, fazendo uso da competência conferida pelo art. 52, X, da Constituição Federal, em sede de recurso extraordinário. O que equivale a aproximadamente 57\% do total de resoluções expedidas no período 1989-2008 em que o Senado faz uso de tal competência.

De acordo com informações extraídas anteriormente, foram expedidas 68 resoluções durante todo o ano de $2005,{ }^{7}$ dentre as quais 43 se referem ao uso efetivo do art. 52, X, da Constituição Federal, o que representa aproximadamente 63\% de todas as resoluções expedidas durante o ano de 2005. Na ocorrência de momentos de "picos", conforme restou demonstrado, é possível depreender que há momentos em que a referida competência se torna efetivamente importante e utilizada, ainda que por motivos desconhecidos, ou que se justifica em razão da inexistência de expedição de resoluções fazendo o uso da competência do art. 52, X, da Constituição Federal nos cinco anos anteriores.

De acordo com as informações extraídas acima, é possível argumentar que há algum tipo de ação estratégica do Senado não só na expedição de suas resoluções, mas no uso efetivo da competência constitucional anteriormente citada. Principalmente, se considerarmos que o Senado Federal esteja modificando a sua forma de atuação ao expedir quantidade menor de resoluções ao longo dos anos, embora se identifique um aumento de suas expedições no que se refere ao uso da competência do art. 52, X, da Constituição Federal. Independentemente dos motivos estratégicos por trás desse padrão de comportamento por parte do Senado, é importante destacar que a instituição tem usado, em grande número, a competência do art. 52, X, se comparado ao número de comunicações das decisões feitas pelo STF.

De fato, embora o número de resoluções expedidas pelo Senado Federal, fazendo uso da competência que lhe confere o art. 52, X, da Constituição Federal, possa ser considerado baixo, em um período de cerca de 20 anos, Há que se destacar que é um 
significativo número se comparado com o número de comunicações feitas pelo Supremo Tribunal Federal. Isso porque, perfazendo a soma das resoluções expedidas pelo Senado, fazendo uso da competência conferida pelo art. 52, X, da Constituição Federal, demonstradas na Tabela 1, é possível obtermos um total de 95 resoluções, enquanto foi possível a identificação de apenas 136 comunicações das decisões do Supremo Tribunal Federal ao Senado.

Dessa forma, tem-se que não é prática reiterada do Senado Federal deixar de expedir resoluções suspendendo eficácia de lei ou ato normativo declarado inconstitucional, consoante o dado analisado anteriormente. Assim, das 136 comunicações feitas ao Senado pelo STF, conforme demonstrado anteriormente, em 95 delas o Senado expediu resolução suspendendo a eficácia da lei ou ato normativo declarado inconstitucional pelo Plenário do STF, o que equivale a aproximadamente $70 \%$ das comunicações feitas. Isto é, das decisões comunicadas pelo STF ao Senado Federal, o Senado se manifesta expedindo resoluções em aproximadamente $70 \%$ das vezes, O que demonstra não ser prática efetiva do Senado Federal a ausência de manifestação quando provocado pelo STF. O que surpreende é o baixo número de comunicações feitas pelo STF ao Senado com base nos números analisados ${ }^{8}$ (97.130 recursos extraordinários providos total ou parcialmente), podendo ter ocorrido por diversos motivos, entre os quais o não envio pelo gabinete dos Ministros, falha na Secretaria de Apoio aos Julgamentos, Coordenadoria dos Acórdãos, isto é, por questões estruturais ou outros motivos até então desconhecidos. Enfim, este conceito aduzido denota, sobretudo, não estarem plenamente atendidos os requisitos necessários para se defender uma autêntica mutação constitucional in casu.

Para justificar a argumentação do Ministro Gilmar Mendes, se fazia necessário que o entendimento lançado por ele acerca do art. 52, X, da Constituição Federal fosse corroborado pela prática das instituições envolvidas. Isto é, o Senado teria de fazer um uso nulo ou insignificante da competência concedida a ele pela Constituição Federal, não sendo esta a hipótese na pesquisa aqui apresentada. O reconhecimento do fenômeno da mutação constitucional precisa necessariamente de uma análise prática, ou seja, precisa da análise das ocorrências de fatos corriqueiros de sentido diverso ao exposto pelo texto constitucional. Frise-se: é a partir dos fatos, dos comportamentos reiterados que há uma mudança de sentido do texto constitucional, e não por métodos interpretativos do texto normativo. Se assim for, não há um fenômeno - o reconhecimento de práticas reiteradas -, mas uma mudança de interpretação do texto constitucional em razão de elementos subjetivos do intérprete.

Assim, não há que se falar em mutação constitucional do disposto no art. 52, X, da Constituição Federal, ao qual o Ministro Gilmar Mendes defende, nos autos da Rcl 4.335-5/ AC, ter o sentido atual de dar mera publicidade às decisões proferidas pelo Supremo Tribunal Federal, assumindo ser desnecessária a concessão da competência atribuída pelo dispositivo ora em comento, e a justificando por razões meramente históricas. E, conforme 
se verificou, embora seja possível argumentar no sentido das raízes históricas da tal competência, não parece se tratar aqui de autêntica mutação constitucional.

\section{IMPLICAÇÕES DA TESE JURÍDICA QUE ATRIBUI NOVO SENTIDO AO ART. 52, X, DA CONSTituiçÃO}

Após décadas de separação entre os sistemas difuso e concentrado de controle de constitucionalidade, surge um entendimento do Ministro Gilmar Mendes no sentido de aproximá-los. No ordenamento jurídico brasileiro, o controle de constitucionalidade é passível de aplicação de forma difusa ou concentrada. O controle concentrado e abstrato de constitucionalidade é caracterizado pela análise da lei em tese, feita por meio de instrumento processual específico. Quando realizada junto ao Supremo Tribunal Federal, os instrumentos processuais hábeis são a ação direta de inconstitucionalidade (genérica), a ação direta de inconstitucionalidade por omissão, a ação direta de inconstitucionalidade interventiva, ${ }^{9}$ a ação declaratória de constitucionalidade e a arguição de descumprimento de preceitos fundamentais. ${ }^{10}$ Os efeitos de tal decisão são considerados erga omnes e vinculantes, o que importa dizer que se estendem a todas as pessoas e têm efeito vinculante. ${ }^{11}$

Diferentemente da espécie de controle acima, o controle difuso se caracteriza pela análise da lei aplicada ao caso concreto, podendo ser feito por diversos instrumentos processuais, como no recurso extraordinário, por exemplo. A (in)constitucionalidade é arguida como causa de pedir, sendo discutida apenas na fundamentação. A decisão a seu respeito não faz coisa julgada material, isto é, não transita em julgado. Essa espécie de controle pode ser feita tanto pelos Magistrados de primeira instância como nos Tribunais de Justiça, Tribunais Regionais e Superiores, desde que realizada de forma incidente. Os efeitos de tais decisões são inter partes e não vinculantes a quem não integra a lide, isto é, são estendidos apenas àqueles que integram a demanda e não tem por obrigação vincular à sua decisão os órgãos do Poder Judiciário. Para que assim seja, faz-se necessária a intervenção do Senado Federal, fazendo uso da competência que lhe é conferida pelo art. 52, X, ${ }^{12}$ da Constituição Federal.

Ressalvadas as peculiaridades de cada espécie de controle, a tese jurídica lançada pelo Ministro Gilmar Mendes no voto proferido nos autos da Rcl 4.335-5/AC tem como objetivo aproximar essas formas de controle de constitucionalidade. De forma que, verificada a (in)constitucionalidade de lei ou ato normativo, pelo Plenário do Supremo Tribunal Federal, em sede de recurso extraordinário, por exemplo, os efeitos de tal julgamento seriam erga omnes e vinculantes. Dentre os argumentos de que se utiliza para alcançar tal entendimento, o de maior desenvolvimento técnico e relevância argumentativa em seu voto foi o de que estamos diante do que o Ministro Mendes acredita ser uma "autêntica mutação constitucional” do art. 52, X, da Constituição Federal. Para o Ministro Gilmar Mendes, tal dispositivo revela outro sentido: o de mera 
atribuição de publicidade às decisões do Supremo pelo Senado Federal, ${ }^{13}$ não precisando nem sequer suspender a execução de lei ou ato normativo declarado inconstitucional.

\section{I Possíveis efeitos da “ABSTRativizaçÃo do CONTROle difuso DE CONSTITUCIONALIDADE"}

Há que se destacar que, embora não seja objeto do presente estudo, faz-se necessário comentar brevemente o impacto que a tese do Ministro Gilmar Mendes pode ter caso seja aceita. Isso porque o estudo realizado trata-se especificamente das condições necessárias ao reconhecimento de uma autêntica mutação constitucional, e não dos efeitos da admissibilidade da tese defendida pelo Ministro Gilmar no voto proferido na Rcl 4.335-5/AC.

Assim, partindo do pressuposto de não mais existir necessidade de expedição de resoluções que suspendam a eficácia das leis ou atos normativos declarados inconstitucionais, poderiam se discutir os mais variados efeitos jurídicos. Um deles seria o da inutilização da súmula vinculante. As súmulas são orientações de julgamentos aos Tribunais e Juízes, dentro da sua competência de atuação. As súmulas do Supremo Tribunal Federal se aplicam a todos os órgãos do Poder Judiciário, por se considerar que o STF é o órgão da máxima hierarquia no Poder Judiciário brasileiro. E, no ano de 2004, a Emenda Constitucional n. 45 permitiu, em seu art. 103-A, ${ }^{14}$ ao Supremo Tribunal Federal a edição de súmulas que não só dessem orientações de julgamento, mas que vinculassem todos os órgãos do Poder Judiciário e a Administração Pública direta e indireta às decisões proferidas pelo Supremo Tribunal Federal.

Nesse sentido, em se tratando de decisões proferidas no controle difuso de constitucionalidade, e não se expedindo resolução do Senado Federal suspendendo a execução das leis ou atos normativos declarados inconstitucionais, haveria clara necessidade de que o próprio Supremo Tribunal Federal editasse súmula que orientasse os demais órgãos do Poder Judiciário e a Administração Pública no tratamento de questões por ele já decididas. E a súmula sendo vinculante, conforme disposto no art. 103-A da Constituição Federal, não orienta um julgamento, mas o vincula. Isto é, não se admite entendimento contrário ao estabelecido pelo Supremo Tribunal Federal e fixado em súmula vinculante. Apesar da necessidade de edição de súmula vinculante na hipótese dos autos da $\mathrm{Rcl}$ 4.335-5/AC, a tese jurídica desenvolvida pelo Ministro Gilmar Mendes, por consequência, a dispensa, tornando-a desnecessária, uma vez que a própria decisão do Plenário do STF, em sede de controle difuso de constitucionalidade, dotaria de eficácia erga omnes e efeitos vinculantes. E mais, uma decisão do Plenário do STF por seis votos a cinco poderia se equivaler a uma súmula vinculante, que possui quorum consideravelmente maior, o que apenas corrobora a sua inutilização (STRECK; OLIVEIRA; LIMA, 2011).

Igualmente ao objetivo da súmula vinculante, como pode ser notado no art. 103-A, $\S 1^{\circ}$, da Constituição Federal, a atribuição de eficácia erga omnes e vinculante às decisões 
do STF em controle difuso pode objetivar a diminuição da incidência de processos e recursos com questões idênticas. No entanto, é possível que tal objetivo não se efetive na prática, porque um dos possíveis efeitos jurídicos, caso prospere a tese jurídica defendida pelo Ministro Gilmar Mendes, seria a possibilidade de se propor Reclamação ${ }^{15}$ perante o STF em relação à não observância, pelos órgãos do Poder Judiciário e da Administração Pública direta e indireta, do entendimento da Corte Constitucional brasileira sobre questões decididas inclusive pelo seu Plenário em sede de controle difuso de constitucionalidade (DIDIER JR., 2006).

Mesmo sabendo que o Supremo Tribunal Federal pode manipular os efeitos de suas decisões, inclusive em controle difuso de constitucionalidade, o STF precisará adotar a cautela necessária na tomada de uma decisão como a dos autos da Rcl 4.335-5 / AC, principalmente sobre os efeitos ex tunc (efeitos retroativos) ou ex nunc (efeitos a partir da data da decisão tomada) de sua decisão; porque, aberta a possibilidade de proposição de reclamações em situações como a descrita acima, será possível imaginar significativo aumento de suas proposições dada a nova importância atribuída às decisões tomadas no controle difuso de constitucionalidade.

Na possibilidade de a tese jurídica do Ministro Gilmar Mendes se tornar admissível pelo Supremo Tribunal Federal, pode ser que o número de interposição de recursos extraordinários aumente consideravelmente, o que vai exigir maior rigor do próprio STF nos filtros a que o recurso extraordinário precisa, necessariamente, passar, como a repercussão geral. Isto é, uma decisão como a que o Supremo Tribunal Federal irá tomar nos autos da $\mathrm{Rcl}$ 4.335-5/AC repercutirá também, em parte, na sua estrutura organizacional, se considerarmos que terá de se reunir para decidir meios ainda mais restritos de se admitir o recurso extraordinário, dado o seu novo desenho e importância no sistema de controle de constitucionalidade brasileiro. ${ }^{16}$

Além das questões já suscitadas, é capaz ainda da dispensa da atuação do Senado Federal em razão de o art. 52, X, da Constituição Federal, representar enorme supressão de competência do Senado pelo STF. Por consequência, estar-se-ia violando o princípio da separação de poderes, principalmente se considerarmos se o STF está adquirindo para si uma competência pertencente a órgão do Poder Legislativo.

Enfim, essas questões podem representar uma mudança radical da estrutura do controle de constitucionalidade de normas no Brasil, ${ }^{17}$ que preserva durante anos a separabilidade entre o controle difuso e o abstrato e concentrado de constitucionalidade. Tal constatação pode ensejar ainda a diversos outros efeitos jurídicos, ${ }^{18}$ mas o mais importante do presente tópico é a demonstração de como uma mudança tão radical na estrutura do controle de constitucionalidade no Brasil, a partir dos efeitos jurídicos do defendido pelo Ministro Gilmar Mendes na Rcl 4.335-5/AC, pode possibilitar à defesa da hipótese de mutação constitucional do art. 52, X, da Constituição Federal. Se tal reconhecimento ensejar em mudanças tão radicais, em qualquer que seja o âmbito de análise da mutação constitucional, ele deve ser questionado. A apresentação de tais questões 
se faz relevante principalmente à demonstração de que deve ser considerada uma condição necessária ao reconhecimento de uma autêntica mutação constitucional à análise dos possíveis efeitos jurídicos de sua admissibilidade, em que qualquer mudança considerável na regulação da vida social pode servir também de limite à sua incidência. Caso prevaleça, o entendimento do Ministro Gilmar Mendes representaria uma revolução nas estruturas do controle de constitucionalidade brasileiro e na separação de poderes.

\section{CONSIDERAÇÕES FINAIS}

Conforme fica demonstrado no presente estudo, os Ministros do Supremo Tribunal Federal às vezes utilizam o seu poder de interpretar a Constituição para alterar as estruturas do controle de constitucionalidade existentes no Brasil, como o fez o Ministro Gilmar Mendes no voto proferido nos autos da Rcl 4.335-5/AC. Ora, sendo o controle de constitucionalidade a forma mais importante e visível de exercício do poder do Judiciário sobre os demais poderes, havendo transformações em suas estruturas, por consequência, também existirá na separação de poderes no Brasil.

No caso aqui analisado, a argumentação do Ministro Gilmar Mendes, ao defender a mutação do art. 52, X, da Constituição Federal, afeta, mesmo que minimamente, a separação de poderes no Brasil. Considerando que não estariam preenchidas as condições necessárias para se falar em autêntica mutação constitucional e que o Senado federal vem cumprindo com a competência que o art. 52, X, da Constituição Federal lhe concede, a competência privativa do Senado lhe estaria sendo suprimida e, ao revés, transferida ao próprio Supremo Tribunal Federal.

Conforme foi exposto anteriormente, dos 97.130 recursos extraordinários providos, total ou parcialmente, pelo Plenário do STF, apenas em 136 houve efetiva comunicação de suas decisões ao Senado Federal, mesmo com o art. 178 do Regimento Interno do STF considerando tal postura como um dever. Isto é, dos recursos extraordinários analisados e providos, total ou parcialmente, apenas $0,1 \%$ teve sua decisão comunicada ao Senado. Na verdade, o próprio Supremo Tribunal Federal não está cumprindo com o seu Regimento Interno, ao qual deveria comunicar tais decisões ao Senado. Tal postura nos permite indagar se a argumentação utilizada ao se defender a desnecessidade de expedição de resolução pelo Senado, para suspender eficácia de norma declarada inconstitucional no controle difuso, não seria uma forma de o STF inutilizar a competência conferida pelo art. 52, X, da Constituição. Isso porque as expedições de resoluções por parte do Senado para o uso efetivo do art. 52, X, da Constituição ocorrem a partir da comunicação das decisões do STF ao Senado Federal. A partir do momento em que tais comunicações não são feitas, o Senado fica impossibilitado de fazer uso da sua competência constitucional.

A argumentação acima descrita pode ser ainda mais plausível ao se verificar o percentual das resoluções expedidas pelo Senado Federal, a partir das comunicações 
feitas pelo STF. De acordo com os dados coletados, das 136 comunicações feitas pelo STF ao Senado Federal, este expediu 95 resoluções suspendendo a eficácia de lei ou ato normativo declarado inconstitucional, o que equivale a aproximadamente $70 \%$ de todas as comunicações feitas. Considerando tal dado, pode não fazer sentido a argumentação de que a competência conferida ao Senado no art. 52, X, da Constituição possui índole meramente histórica ou que não faça uso efetivo de tal competência.

A partir desse tipo de análise, percebeu-se que o STF utiliza sempre os meios que lhe são legítimos, isto é, da sua jurisprudência e argumentação tipicamente constitucional, para ampliar de forma significativa os seus poderes e forma de atuação. Principalmente, por meio das mais variadas teses jurídicas lançadas na ordem jurídica brasileira. Por exemplo, no caso proposto, foi demonstrado como um simples argumento de alegação de mutação de determinado dispositivo constitucional é capaz de gerar as mais diversas transformações no sistema de controle de constitucionalidade do Brasil e, por consequência, na separação de poderes.

O uso ilegítimo da mutação constitucional pode gerar como possível consequência a possibilidade de os Ministros do Supremo Tribunal Federal estarem reformando silenciosamente a Constituição Federal por meio de interpretação e argumentação. Isto é, o Supremo Tribunal Federal estaria modificando, por meio de sua própria decisão, o arranjo institucional que lhe fora disposto na Constituição de 1988. E quando o direito e as instituições se transformam por meio de interpretações judiciais, tais mudanças jurídicas devem ser discutidas por se tratarem de mudanças feitas por órgãos não legislativos. Como o acúmulo das funções de autoridade com exercício de poder deveriam ser restritos aos órgãos representativos, submetidos a um controle de ordem democrática, a discussão acerca da nova postura do Supremo Tribunal Federal faz-se fundamental à compreensão do novo cenário jurídico e político ao qual estamos inseridos. Por estarmos diante de um momento histórico em que a promulgação da Constituição completou pouco mais de vinte e cinco anos, o debate que tramita em seu entorno continua relacionado ao princípio democrático, mas sob um novo enfoque: o do enfraquecimento de algumas instituições democráticas em detrimento da atuação fortalecida de outras, nos remetendo a uma nova estrutura da democracia constitucional brasileira. 


\section{NOTAS}

* O texto foi produzido a partir de pesquisa realizada, sob a orientação do Prof. Diego Werneck Arguelhes, no âmbito da FGV Direito Rio. A pesquisa completa está disponível no vol. 1 da Coleção Jovem Jurista - Revista da FGV Direito Rio que apresenta coletânea dos melhores trabalhos de conclusão de curso de cada ano -, em: SANTOS, Carlos Victor Nascimento dos. Mutação constitucional do controle difuso no Brasil? Uma análise do papel do Senado diante do art. 52, X, da Constituição. In: Coleção Jovem Jurista, v. 1. Rio de Janeiro: Escola de Direito da Fundação Getulio Vargas, 2010, p.151-202.

1 São considerados limites materiais à modificação do texto constitucional:

"Art. 60. [...]

$\S 4^{\circ}$ - Não será objeto de deliberação a proposta de emenda tendente a abolir:

I - a forma federativa de Estado;

II - o voto direto, secreto, universal e periódico;

III - a separação dos Poderes;

IV - os direitos e garantias individuais".

2 As normas constitucionais deverão observar, assim, o novo sentido de seu texto normativo para terem a sua aplicabilidade aos casos concretos. Isso não importa dizer que são normas de eficácia contida, sob a alegação de que dependem de uma complementação, via de regra legislação infraconstitucional, para serem completamente eficazes. Com a mutação constitucional, a norma constitucional mantém o seu status de norma de eficácia plena, contida ou limitada, transformando-se apenas o sentido que uma palavra possuía no texto normativo, mas mantendo-se os efeitos, quanto à sua aplicabilidade, anteriores à mutação constitucional realizada (BULOS, 1996, 34-43).

3 Foi estudado o número de acórdãos proferidos pelo Plenário do Supremo Tribunal Federal porque somente estes são enviados ao Senado Federal para o exercício da competência que lhes concede o art. 52, X, da Constituição Federal, além da defesa do Ministro Gilmar Mendes de que os acórdãos proferidos pelo Plenário do STF não precisariam de nova análise da sua questão constitucional, uma vez que ele próprio já o havia analisado.

4 O spider é um software que utiliza a coleta e filtragem de dados da internet, de campos selecionados pelo usuário, como sites etc., a fim de agregar informações de forma organizada para que o usuário de seu software possa ter acesso. In casu, o pesquisador da Fundação Getulio Vargas fez a sua coleta e filtragem de dados somente no site do Supremo Tribunal Federal, agregando e organizando as informações de forma a acessá-las de forma mais simplificada. Ver artigo disponível em: <http://www.ibm.com/developerworks/br/library/l-spider/>. Acesso em: 3 maio 2010.

5 BRASIL. Regimento Interno do Supremo Tribunal Federal. Disponível em: <http://www.stf.jus.br/arquivo/cms/ legislacaoRegimentoInterno/anexo/RISTF_fevereiro_2010.pdf>. Acesso em 13 mar. 2010:

“Art. 178. Declarada, incidentalmente, a inconstitucionalidade, na forma prevista nos arts. 176 e 177, far-se-á comunicação, logo após a decisão, à autoridade ou órgão interessado, bem como, depois do trânsito em julgado, ao Senado Federal, para os efeitos do art. 42, VII, da Constituição" (grifou-se).

Vale lembrar que o dispositivo da Constituição a que o dispositivo acima se refere é, atualmente, o art. 52, X.

6 Vale lembrar que, mesmo em relação aos que foram julgados parcialmente, separaram-se os que tiveram declaração de inconstitucionalidade de lei ou ato normativo e, posteriormente, foram enviados ao Senado para o exercício da competência conferida pelo art.52, X, da Constituição Federal.

7 Disponível em: <http://www.senado.gov.br/sf/publicacoes/anais/pdf/Resolucoes/2005.pdf>. Acesso em 5 maio 2010

8 Vale ressaltar que o Regimento Interno do Supremo Tribunal Federal, em sua versão mais atualizada (fev. 2010), dispõe em seu art. 178 sobre a obrigatoriedade da Corte Constitucional em enviar as decisões definitivas que proferirem em sede de controle difuso de constitucionalidade ao Senado Federal. Lembrando que o dispositivo a que o art. 178 se refere, atualmente é o art. 52, X, da Constituição Federal. Vejamos:

"Art. 176. Argüida a inconstitucionalidade de lei ou ato normativo federal, esta dual ou municipal, em qualquer outro processo submetido ao Plenário, será ela julgada em conformidade com o disposto nos arts. 172 a 174, depois de ouvido o Procurador-Geral.

$\S 1^{\circ}$ Feita a argüição em processo de competência da Turma, e considerada relevante, será ele submetido ao Plenário, independente de acórdão, depois de ouvido o Procurador-Geral. 
$\S 2^{\circ}$ De igual modo procederão o Presidente do Tribunal e os das Turmas, se a inconstitucionalidade for alegada em processo de sua competência.

Art. 177. O Plenário julgará a prejudicial de inconstitucionalidade e as demais questões da causa.

Art. 178. Declarada, incidentalmente, a inconstitucionalidade, na forma prevista nos arts. 176 e 177, far-se-á comunicação, logo após a decisão, à autoridade ou órgão interessado, bem como, depois do trânsito em julgado, ao Senado Federal, para os efeitos do art. 42, VII, da Constituição" (grifou-se).

(BRASIL. Regimento Interno do Supremo Tribunal Federal. Disponível em: <http://www.stf.jus.br/arquivo/ cms/legislacaoRegimentoInterno/anexo/RISTF_fevereiro_2010.pdf>. Acesso em 13 mar. 2010)

9 A ação direta de inconstitucionalidade interventiva surgiu com a Emenda Constitucional n. 45, que acrescentou o inciso III ao art. 36 da Constituição Federal, e se apresenta como um dos pressupostos à decretação da intervenção, vejamos:

“Art. 36. A decretação da intervenção dependerá:

$[\ldots]$

III - de provimento, pelo Supremo Tribunal Federal, de representação do Procurador-Geral da República, na hipótese do art. 34, VII, e no caso de recusa à execução de lei federal”.

De acordo com Clémerson Merlin Cléve, a ADI interventiva deve ser entendida como o "[...] procedimento fincado a meio caminho entre a fiscalização da lei in thesi e aquela realizada in casu. Trata-se, pois, de uma variante da fiscalização concreta realizada por meio da ação direta" (CLÉVE, 1993, p. 125).

10 É possível também realizar tal controle perante os Tribunais de Justiça, por meio da representação de inconstitucionalidade, em razão do princípio da simetria. A inconstitucionalidade é arguida no pedido, ao qual deve integrar o dispositivo do acórdão, estando ele revestido pela coisa julgada material.

11 Art. 102, $\S 2^{\circ}$, da CF: " $\S 2^{\circ}$ As decisões definitivas de mérito, proferidas pelo Supremo Tribunal Federal, nas ações diretas de inconstitucionalidade e nas ações declaratórias de constitucionalidade produzirão eficácia contra todos e efeito vinculante, relativamente aos demais órgãos do Poder Judiciário e à administração pública direta e indireta, nas esferas federal, estadual e municipal”.

12 Art. 52, X, da CF: "Art. 52. Compete privativamente ao Senado Federal:

$[\ldots]$

$\mathrm{X}$ - suspender a execução, no todo ou em parte, de lei declarada inconstitucional por decisão definitiva do Supremo Tribunal Federal".

13 Em relação a essa competência do Senado Federal, apesar de atualmente já se ter posição majoritária a respeito, muita controvérsia já surgiu a seu respeito. Ocorrendo o evento que enseje a aplicação do art. 52, X, deverá o Senado Federal suspender a execução da lei, ou tão somente poderá fazê-lo? Alguns autores como Alfredo Buzaid e Celso Ribeiro Bastos (ambos citados por Paulo Brossard [1976]) defendiam a atividade vinculada do Senado, razão pela qual deveriam suspender a execução de lei ou ato normativo diante da incidência do art. 52, X, da Constituição, sob a alegação de que teriam o dever de examinar a ocorrência dos pressupostos constitucionais à declaração de inconstitucionalidade das normas.

No entanto, diversamente da hipótese de que o Senado deve suspender a eficácia de lei ou ato normativo, diante da hipótese do art. 52, X, da Constituição, predomina o entendimento do caráter político-discricionário da competência atribuída ao Senado pelo art. 52, X, da Constituição (BARROSO, 2006). E a inexistência de sanção ao Senado em caso da não utilização de tal competência é um dos principais argumentos sustentados pela doutrina majoritária para justificar tal discricionarismo político.

Além disso, o próprio Senado Federal, desde a Res. n. 13/91, que acrescentou o inciso II ao art. 91 do seu Regimento Interno, afirma a possibilidade de se deliberar a respeito do evento previsto no art. 52, X, da Constituição, confirmando o entendimento do caráter político-discricionário do dispositivo. Vejamos:

"Art. 91. Às comissões, no âmbito de suas atribuições, cabe, dispensada a competência do Plenário, nos termos do art. 58, § $2^{\circ}$ da Constituição, discutir e votar:

$[\ldots]$

II - projetos de resolução que versem sobre a suspensão da execução, no todo ou em parte, de lei declarada inconstitucional por decisão definitiva do Supremo Tribunal Federal”. (Obs.: o art. da Constituição a qual o artigo se refere é o atualmente art. 52, X, da Constituição Federal.)

Assim, resta claro que o Senado adota a posição de que a competência atribuída pelo dispositivo constitucional é político-discricionária.

14 “Art. 103-A. O Supremo Tribunal Federal poderá, de ofício ou por provocação, mediante decisão de dois terços 
dos seus membros, após reiteradas decisões sobre matéria constitucional, aprovar súmula que, a partir de sua publicação na imprensa oficial, terá efeito vinculante em relação aos demais órgãos do Poder Judiciário e à administração pública direta e indireta, nas esferas federal, estadual e municipal, bem como proceder à sua revisão ou cancelamento, na forma estabelecida em lei.

$\S 1^{\circ}$ A súmula terá por objetivo a validade, a interpretação e a eficácia de normas determinadas, acerca das quais haja controvérsia atual entre órgãos judiciários ou entre esses e a administração pública que acarrete grave insegurança jurídica e relevante multiplicação de processos sobre questão idêntica.

$\S 2^{\circ}$ Sem prejuízo do que vier a ser estabelecido em lei, a aprovação, revisão ou cancelamento de súmula poderá ser provocada por aqueles que podem propor a ação direta de inconstitucionalidade.

$\S 3^{\circ}$ Do ato administrativo ou decisão judicial que contrariar a súmula aplicável ou que indevidamente a aplicar, caberá reclamação ao Supremo Tribunal Federal que, julgando-a procedente, anulará o ato administrativo ou cassará a decisão judicial reclamada, e determinará que outra seja proferida com ou sem a aplicação da súmula, conforme o caso”.

15 “Art. 102. Compete ao Supremo Tribunal Federal, precipuamente, a guarda da Constituição, cabendo-lhe:

I - processar e julgar, originariamente:

$[\ldots]$

l) a reclamação para a preservação de sua competência e garantia da autoridade de suas decisões;"

16 Há de se acrescentar ainda a possibilidade de responsabilização civil do Estado baseado na declaração de normas inconstitucionais (PINTO, 2008, p. 189-190). Tal evento ocorre quando o cidadão é lesado por normas jurídicas que, após produzirem seus regulares efeitos, são declaradas inconstitucionais in abstracto pelo Supremo Tribunal Federal. A título de exemplo, poderia o Estado criar lei que limitasse a observância da capacidade contributiva do contribuinte do Imposto de Renda (IR) e o fizesse pagar IR consideravelmente mais alto. Além da lesão à sua fonte de renda e do sustento de sua família, vários danos podem lhe ser causados, como a impossibilidade de abertura de plano de saúde de familiares seus que necessitam com urgência da medida, por exemplo. Com a declaração da inconstitucionalidade de tal lei, in abstracto, poderia o cidadão deste exemplo requerer judicialmente a responsabilização civil do Estado baseado na declaração de inconstitucionalidade da lei.

No mesmo sentido, a equiparação entre os efeitos da decisão proferida pelo STF, nos controles abstrato e difuso de constitucionalidade, pode aumentar consideravelmente as demandas em face do Estado por responsabilização civil baseado na declaração de normas inconstitucionais. Isso porque não é difícil a percepção de que existem muito mais normas declaradas inconstitucionais incidentalmente do que in abstracto. Tal postura poderia gerar enorme prejuízo à Administração Pública, podendo o Estado ser comumente processado e obrigado a ressarcir o cidadão por conta do dano injusto por ele causado ao editar normas que levassem os cidadãos a incorrer em determinado dano.

17 Vale destacar que a equiparação entre os efeitos da decisão, proferida pelo STF, no controle difuso e abstrato de constitucionalidade nos leva à percepção de mais um efeito jurídico que não será profundamente abordado neste estudo: o da possibilidade de, caso a tese jurídica do Ministro Gilmar Mendes aqui discutida se consagre vencedora, um clube de futebol utilizando do recurso extraordinário, por exemplo, julgado pelo Plenário do STF, mesmo fazendo o controle incidental de normas, consiga a atribuição de efeitos erga omnes e vinculante à decisão. Tal situação se assemelharia à hipótese de um não legitimado pelo art. 103 da Constituição Federal fazer controle abstrato de constitucionalidade, porém em via difusa. Logo, poderíamos considerar tal evento como a criação de uma espécie de "Adin individual”, ou considerar o surgimento de uma espécie de "controle abstrato de constitucionalidade em via difusa", também por isso a denominada "abstrativização do controle difuso de constitucionalidade".

18 É interessante destacar que outro importante efeito jurídico é o da possibilidade do controle difuso de constitucionalidade gerar efeitos equiparáveis aos do controle abstrato. Aceita a tese jurídica do Ministro Gilmar Mendes, em que aproxima o controle difuso do concentrado e abstrato de constitucionalidade, a decisão em sede de recurso extraordinário ou habeas corpus, terá os seus efeitos mais próximos dos gerados em controle abstrato de constitucionalidade.

Coincidência ou não, durante o discurso proferido pelo Ministro Gilmar Mendes na sabatina feita pelo Senado Federal sobre a sua indicação para Ministro do Supremo Tribunal Federal, no dia 15 de maio de 2002, fora defendido por ele uma tendência de aproximação dessas diferentes espécies de controle. Vejamos trecho de tal discurso: "Tal jurisdição, exatamente por prestar a toda a coletividade, deve estar sujeita à disciplina específica e singular no que toca às formas de sua provocação e à repercussão de suas decisões. Em particular, a transcendência destina-se a racionalizar a provocação da jurisdição constitucional de modo a assegurar a intervenção do Supremo Tribunal Federal seja preservada para aquelas hipóteses em que se verifica controvérsia constitucional verdadeiramente relevante e de alcance geral.

Tal disciplina, combinada com a ampliação da eficácia das decisões do Supremo Tribunal Federal, haverá de assegurar a mais adequada socialização da prestação da jurisdição constitucional de nossa Excelsa Corte, pois não apenas qualificará 
o interesse público em sua manifestação, como também assegurará a tendência e eficácia universal do que decidir" (grifou-se). Disponível em: <http://www.conjur.com.br/2009-set-24/imagens-historia-dia-gilmar-mendes-foi-sabatinado>. Acesso em: 14 maio 2010 .

\section{REFERÊNCIAS BIBLIOGRÁFICAS}

ANÁLISE JUSTIÇA. São Paulo: Análise Editorial, n. 1, ano 1, 2006.

BARROSO, Luís Roberto. O controle de constitucionalidade no direito brasileiro. 2. ed. São Paulo: Saraiva, 2006. BROSSARD, Paulo. O Senado e as leis inconstitucionais. Revista de Informação Legislativa, Brasília, abr.-jun. 1976. BULOS. Uadi Lammêgo. Curso de direito constitucional. São Paulo: Saraiva, 2007. jan.-mar. 1996.

. Da reforma à mutação constitucional. Revista de Informação Legislativa, Brasília, ano 33, n. 129,

CLÉVE, Clémerson Merlin. Fiscalização abstrata da constitucionalidade no direito brasileiro. São Paulo: Revista dos Tribunais, 1993.

DIDIER JR., Fredie. Transformações do recurso extraordinário. In: FUX, Luiz; NERY JÚNIOR, Nelson; WAMBIER, Teresa Arruda Alvim (Coords.). Processo e Constituição. Estudos em homenagem ao professor José Carlos Barbosa Moreira. São Paulo: Revista dos Tribunais, 2006.

FERRAZ, Anna Cândida da Cunha. Processos informais de mudança da Constituição: mutações constitucionais e mutações inconstitucionais. São Paulo: Max Limonad, 1986.

LOEWENSTEIN, Karl. Teoría de la Constitución. 2. ed. Barcelona: Editorial Ariel, 1986.

MAZZOTTI, Alda Judith Alves; GEWANDSZNAJDER, Fernando. O método nas ciências naturais e sociais: pesquisa quantitativa e qualitativa. 2. ed. São Paulo: Thomson, 2004.

MENDES, Gilmar Ferreira; COELHO, Inocêncio Mártires; BRANCO, Paulo Gustavo Gonet. Curso de direito constitucional. São Paulo: Saraiva, 2007.

Paulo: Saraiva, 2009.

Direitos fundamentais e controle de constitucionalidade: estudos de direito constitucional. 3. ed. São

. Jurisdição constitucional. 5. ed. São Paulo: Saraiva, 2005.

O papel do Senado Federal no controle federal de constitucionalidade: um caso clássico de mutação constitucional. Revista de Informação Legislativa, Brasília, ano 45, n. 179, jul.-set., 2008.

PINTO, Helena Elias. Responsabilidade civil do Estado por omissão - Na jurisprudência do Supremo Tribunal Federal. Lumen Juris Editora: Rio de Janeiro, 2008.

STRECK, Lênio Luís; OLIVEIRA, Marcelo Andrade Cattoni; e LIMA, Martonio Mont'Alverne Barreto. A nova perspectiva do Supremo Tribunal Federal sobre o controle difuso: Mutação constitucional e limites da legitimidade da Jurisdição Constitucional. Disponível em: < www.leniostreck.com.br/site/wpcontent/uploads/2011/10/4.pdf>.

VERÍSSIMO, Marcos Paulo. A Constituição de 1988, vinte anos depois: Suprema Corte e ativismo judicial à "brasileira". Revista DIREITO GV, São Paulo, n. 2, ano 4, jul.-dez., 2008.

VIEIRA, Oscar Vilhena. Supremocracia. Revista DIREITO GV, São Paulo, n. 8, 2009.

\section{Carlos Victor Nascimento dos Santos}

